\title{
Speed Identification Based on Surveillance Video in Traffic Accidents
}

\author{
Xu Shuquan ${ }^{1}$, Yang Shengwen ${ }^{2}$, Chen Chaozhou ${ }^{1}$, Wu Guofang ${ }^{1}$ \\ ${ }^{1}$ Research Institute of Highway Ministry of Transport, Beijing, China \\ sq.xu@rioh.cn, cz.chen@rioh.cn,gf.wu@rioh.cn \\ ${ }^{2}$ Traffic Science Research Institute of Yunnan Province, China, 59188660@qq.com
}

\begin{abstract}
Traditional analytical methods on the velocity in traffic accident are summarized, and the use of reference object in vehicle-mounted surveillance video data identifying the velocity in traffic accidents was introduced. A collision between a bus and an electric bicycle which caused injuries was taken as an example, the velocity of buses and electric bicycle before the incident were calculated, and the braking process of the bus was analyzed, and the results were checked based on brake marks. Through the comparison, the velocity of the bus calculated by the vehicle-mounted surveillance video data, the discrepancy was only $0.19 \mathrm{~km} / \mathrm{h}$. According to the velocity obtained from brake marks, which showed that the applicability of the results calculated by vehicle-mounted surveillance video is preferable.
\end{abstract}

Key words: traffic accidents, identification of velocity, vehicle-mounted surveillance video

\section{INTRODUCTION}

In the process of traffic accidents, it was a big liability issue whether you can determine before the occurrence of the accident and the instant motion state (line, position, velocity) and correct (reasonable) description of transient motion of both parties, which was not only concerned with the scientifically analysis of the causes, justly process of accidents, and the corresponding punishment to the perpetrators ,but also related to the maintenance of authority for law enforcement officers in traffic accidents and the maintenance of the prestige issue for the party and the government among the masses.

Foreign scholars carried out the velocity identification of vehicle accident earlier, Cooper put forward the use of brake marks on the scene to calculate their driving velocity. Neprune divided deceleration into two parts based on the deceleration curve of braking, one part in proportion to the time, the other is constant.Taiwan scholars studied the relevant parameters that affect braking distance and achieved certain results. The widely used standards in China now was made by the Ministry of Public Security Traffic Management Research Institute "technical appraisal of vehicle velocity in typical accident". Li Guangxu et al. described the accident in the vehicle identification methods based on kinematics and mechanics. On the basis of these studies, this paper intended to analyze the data of the vehicle-mounted surveillance video to identify the velocity of the vehicle.

\section{MEthodology}

Two references that were easy to measure were selected from the surveillance video, such as the center guide line or the two endpoints of road divider. The distance between two reference was measured, set the distance as $\Delta l$, and a feature point was selected in the body of the vehicle, supposed the time interval required for feature point passing the $\Delta l$ as $\Delta t$. The average speed $\mathrm{V}$ could be obtained 
from the displacement $\Delta l$ divide the interval time $\Delta t$.

The detail procedures were as follows:

Using the video player to check the video frame by frame, determining the frame numbers within the unit time (1 second), calculating the time interval between two neighbor frames, the time interval is set as $\Delta t$ '.

According to the travel route in the vehicle-mounted surveillance video, select two references easy to measure the distance, joints, such as two separation line endpoints in the center of the road, crosswalk or concrete pavement edge.

According to the travel path and the reference positions in the vehicle-mounted surveillance video, a certain part of the body is confirmed as the feature points, such as selecting the leading edge of the front or rear of the vehicle.

Playing the surveillance video frame by frame, making the feature points pass the first reference (such as the front of the separation line of the road center) and take it as the first frame, when passing the second reference (such as the end of the separation line of the road center ), take it as the $\mathrm{N}$ frame.

According to the traveling direction of the vehicle, the distance between two references were measured as $\Delta l$. The average speed of the vehicles could be calculated according to formula in mechanics, as shown in Equation 1:

$$
v=\frac{\Delta l}{\Delta t}=\frac{\Delta l}{(N-1) \Delta t^{\prime}}
$$

\section{INSTANCE ANALYSIS}

On April 13,2013, a traffic accident happened at 10:30.A bus collided with an electric bicycle, the accident leaded the electric bicycle rider got hurt.

\section{A. The accident process analysis}

Based on the surveillance video data provided by the traffic police (Fig. 1):2013-04-13

10:24:44 (in seconds) 19 frame: the rider collided with isolation fence

45 seconds 16 frames: the rider fell down.

45 seconds 24 frames: the rider entered into the blind area;

46 seconds 2 frames: the rider was collided out of the blind area;

46 seconds 20 frames: the bus stopped moving;

47 seconds 13 frames: the rider stopped moving.

Based on the blind area time when the cyclist got in and got out, the collision time was at 46 seconds 0 frame.

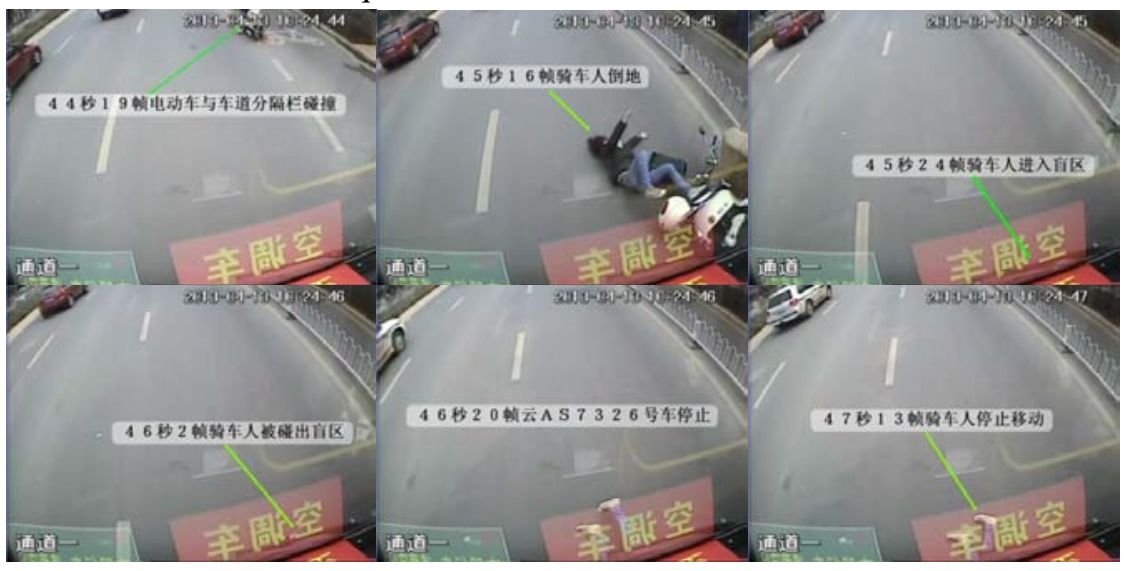

Fig. 1 The surveillance video of the accident. 


\section{B. Speed analysis and calculation}

a.The calculation of electric bicycle speed

Through the video data (Fig.2 a, 2 b): at 2013-04-13 10:24:39 14 frames, the rear wheel of the electric bicycle pressed in the end of the roadway direction arrow. At 40 seconds 13 frames, the rear wheel of the electric bicycle pressed in front of the roadway direction arrow.

After measuring, the length of motor vehicle oriented arrow was 6 meters. This period of time was 0.96 seconds. The speed of the motor vehicle was $22.5 \mathrm{~km} / \mathrm{h}$ on average from 39 seconds 14 frame to 40 seconds 13 frame by computation.

b.The calculation of bus speed

As shown in figure 2c: the lower left corner in the monitor screen was set as the origin of right angle coordinate system; the spaces of the lane line or the solid line were set as the scale, the tracking points were set before and after the scale, played the video frame by frame until the scale was out of the screen. The motion tracking software was used to export the $\mathrm{X}$ and $\mathrm{Y}$ value of the tracking points in each frame.

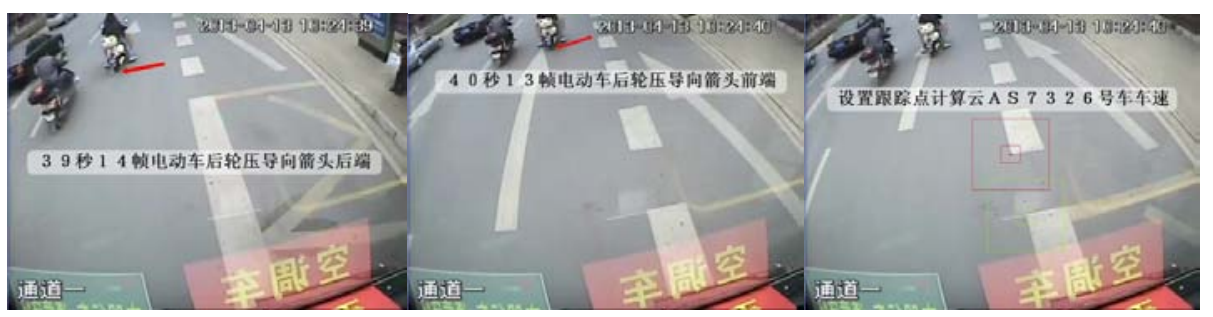

(a)

(b)

(c)

Fig.2 The references in calculating the speed of electric bicycle and bus.

The rate of the video frame was $25 \mathrm{fps}$, which means the video data of 1 second contained 25 frames, the interval was 0.04 second. In this case, the space of the lane line or the solid line were set as the scale $\mathrm{L}$. The length of the solid (spaces) line in station was $1 \mathrm{~m}$, the space of the motorway lane line was $4 \mathrm{~m}$ and the solid line of the motorway lane line was $2 \mathrm{~m}$.

A value from the post-tracking point was randomly chose and set the related frame as A, and the $\mathrm{Y}$ value of the front-tracking point as $\mathrm{Y} 1-\mathrm{A}$, and the post-tracking point as Y2-A, thus, the scale of the frame $A$ was (Y1-A-Y2-A). The closest value to the Y1-A in the $\mathrm{Y}$ value of the post-tracking point was picked out and set the related frame as $B$, and the value was Y2-B. Thus, the picture travel distance of the vehicle from A frame to B frame was (Y2-B-Y2-A), the real travel distance of the vehicle was $\mathrm{SA}-\mathrm{B}=$ L*(Y2-B-Y2-A)/ (Y1-A- Y2-A).

Set the interval from A frame to the B frame was $i$, the interval time was $\Delta \mathrm{t}^{\prime}=\mathrm{i}^{*} 0.04$.
According to the equation:

$$
\begin{gathered}
\mathrm{V}_{\mathrm{A}-\mathrm{B}}=\mathrm{S}_{\mathrm{A}-\mathrm{B}} / \mathrm{t}_{\mathrm{A}-\mathrm{B}}=\mathrm{L} *\left(\mathrm{Y}_{2-\mathrm{B}}-\mathrm{Y}_{2-\mathrm{A}}\right) / \\
\left(\left(\mathrm{Y}_{1-\mathrm{A}}-\mathrm{Y}_{2-\mathrm{A}}\right) * \mathrm{i} * 0.04\right)
\end{gathered}
$$

The average speed from the $A$ frame to the $\mathrm{B}$ frame was VA-B. In this way, a group of the average speeds could be calculated. Based on the theory that the instantaneous velocity of the midpoint is equal to the average speed, time-speed curves were built.

The time- velocity diagram from 10:24:35 18 frame to $10: 24: 4620$ frame was shown in Fig.3.

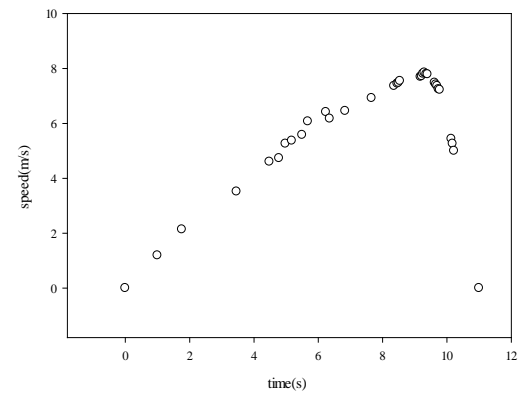

Fig.3 The time-velocity diagram of bus, from 10:24:35 18 frame to 10:24:46 20 frame.

The bus had experienced a staring-acceleration-deceleration-stop process 
which last for 11.08s (from 10:24:35 18 frame to $10: 24: 4620$ frame).The maximum speed was about $28.26 \mathrm{~km} / \mathrm{h}(7.85 \mathrm{~m} / \mathrm{s})$ at 10:24:45.

\section{Analysis of the braking process}

a.The decreasing and the collision speed

According to the tracking data, the bus braking time-velocity diagram from 45 s frame to 46 s 20 frame were shown in figure 4:

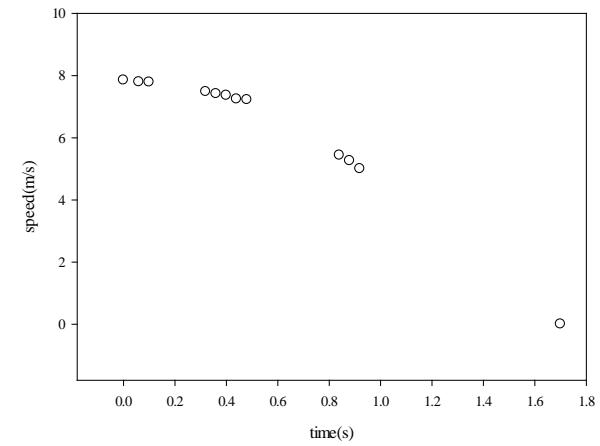

Fig. 4 The time- velocity diagram of bus, from 10:24:45 0 frame to 10:24:46 20 frame.

From the bus braking time-speed curve (Fig. 4), there was a distinct variation, suggested a rising braking force and a constant braking force during the braking deceleration process. From 45.1 seconds to 45.48 seconds, the bus experienced a rising braking force. Based on the motion equation $y=-1.5223 Y+7.9504$, the speed of the braking deceleration was 1.5223 $\mathrm{m} / \mathrm{s}^{2}$.

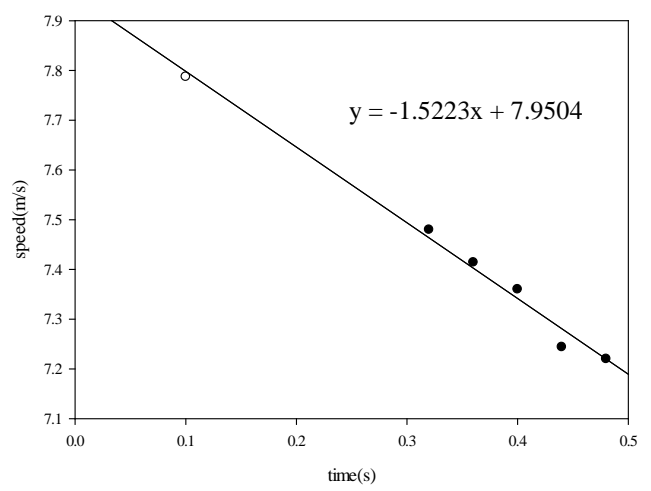

Fig. 5 The time-velocity regression diagram of bus, from 45.1 s to $45.48 \mathrm{~s}$.

From 45.48 seconds to 46.48 seconds, the bus experienced a constant force braking process. The motion equation was $\mathrm{y}=6.0356 \mathrm{Y}+10.4015$. Based on the equation, the braking deceleration was $6.0356 \mathrm{~m} / \mathrm{s}^{2}$.
The collision time was at $46 \mathrm{~s}$, set $\mathrm{Y}=1$ and the $y$ was $15.72 \mathrm{~km} / \mathrm{h}$ based on the equation.

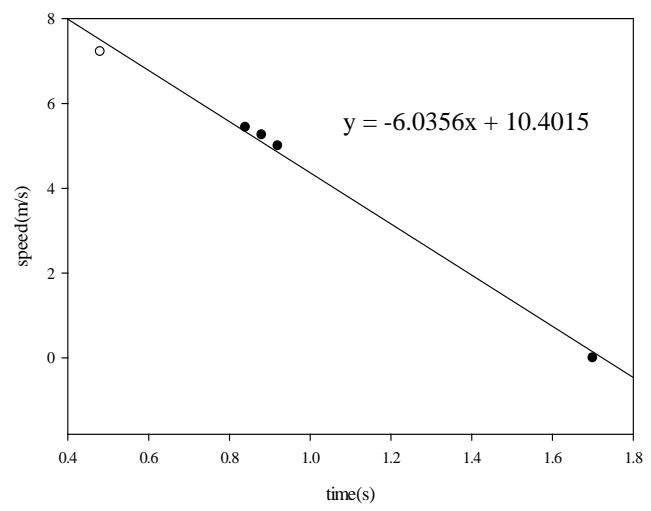

Fig.6 The time-velocity regression diagram of bus, from 45.48 s to $46.48 \mathrm{~s}$.

b.The time and distance

At 44.76 seconds, the electric bicycle collided with guardrail and at 45.1 seconds, the bus began to brake, the reaction time was 0.86 seconds. The braking process last 1.72 seconds including two procedures, the first procedure last $0.38 \mathrm{~s}$ from $45.1 \mathrm{~s}$ to $45.8 \mathrm{~s}$ with a rising braking force, followed by a constant force braking process which last 1 s from 45.48 to 46.48 .

At 44.76 seconds electric bicycle collided with the guardrail, based on the separation line of the exit, the distance between the bus and the electric bicycle was 6 meters.

According to data provided by the traffic police, brake marks of the bus left on the spot were $4 \mathrm{~m}$ in the left-rear corner and $4.6 \mathrm{~m}$ in the right-rear corner. Take the longest traces for checking.

According to the formula: $V=\sqrt{2 \mathrm{as}}$

Take $\mathrm{a}=6.0356 \mathrm{~m} / \mathrm{s}^{2}, \mathrm{~S}=4.6 \mathrm{~m}$.

Results: the speed when the brake mark appeared: $\mathrm{Vbr}=7.45 \mathrm{~m} / \mathrm{s}=26.82 \mathrm{~km} / \mathrm{h}$; the result calculated from the video data was $\mathrm{V}_{\text {video }}$ speed $=7.50 \mathrm{~m} / \mathrm{s}=27.01 \mathrm{~km} / \mathrm{h}$; the difference is $0.19 \mathrm{~km} / \mathrm{h}$.

c. Performance evaluation of the bus braking According to GB 7258 standards, the mean decreasing speed of the bus which is full of the 
passengers should be larger than $5.8 \mathrm{~m} / \mathrm{s}^{2}$. Based on the video, the average deceleration speed was calculated as 6.0356 $\mathrm{m} / \mathrm{s}^{2}$.Therefore, the bus braking performance accord with the GB 7258 .

d. Discussion of the revised adhesion coefficient

According to the data provided by the traffic police, the braking traces left by the bus at the scene was 4 meters at left-rear corner and 4.6 meters at right-rear corner; In addition, there were not any braking traces in the front wheel and the road was made of dried asphalt. Considering the route for the new pavement, we defined adhesion coefficient as 0.7 . According to formulation: $\mathrm{a}=\mu \mathrm{gk}$, the $\mathrm{k}$ was 0.88 .

\section{Result}

a.The electric bicycle ran into the motorway illegally; before the accident, the speed of the electric bicycle was $22.5 \mathrm{~km} / \mathrm{h}$, which had overspeed; the primary reason of this accident was the collision of the electric bicycle with the guardrail, which leaded the electric bicycle fall in the motorway.

b.Braking performance of this bus was in agreement with GB 7258 standards requirements.

c.The bus before the accident just started acceleration .The top speed was only 28.26 $\mathrm{km} / \mathrm{h}$ without overspeed. The total reaction time was 0.86 seconds, the driver had no improper behavior.

\section{CONCLUSION}

Based on the vehicle-mounted surveillance video data, using the reference material related to the site distance, the rate of video image and the starting point and end point of the single frame image in the traffic accident together, we could calculate the real-time speed of both the electric bicycle and bus at the time. Combining with the braking track on the scene, we considered that the electric bicycle was overspeed in the motorway and the fall of the electric bicycle was the main reason of this accident. The bus had no overspeed behavior and the breaking performance was qualified. It is a relatively practical method to identify the car speed through the vehicle-mounted surveillance video data in traffic accidents, especially in the case of the accident without the evidences such as the tire marks, fall-outs. Further researches and promotion should be conducted to this method.

\section{REFERENCES}

[1] G.W. Cooper, Work, Energy, and Speed from Damage in Traffic Accidents, Topic 870 of the Traffic Accident Investigation Manual, Northwestern University Traffic Institute, 1990.

[2] J. A. Neptune, J.E. Flynn, P.A. Chavez and H.W. Underwood, Speed from Skids: A Modern Approach, SAE Paper No. 950354, 1995.

[3] Lin Dayu, Liao Qingqiu. Testing and study of Chinese automobile braking distance and driving speed relationship. Department of Transportation Institute of Transportation. Republic of China 84 years.

[4] Lin Fengfu, Liao Qingqiu. Testing and study of the braking distance and driving speed's impacting relationship. Department of Transportation Institute of Transportation. Republic of China 86 years.

[5] GA/T 643-2006. Typical accident form vehicle speed technical appraisal [S]. 2006.

[6] Li Guangxu, Yang Zhaoxiang, Zhou Wenzheng. The vehicle identification methods of accident-advantage the momentum conservation to calculate the speed[J]. Traffic World, 2012 (24) :90-91.

[7] Li Guangxu, Yang Zhaoxiang, Zhou Wenzheng. The vehicle identification methods of accident-advantage the projectile formula to calculate the speed. Traffic World, 2012 (20) :134-135. 